\title{
Analysis of waste heat recovery technology of hot forging cooling system*
}

\author{
Hui Chen ${ }^{\mathrm{a}}$, Chun-Hui Bai ${ }^{\mathrm{b}}$ and Qi-Chen Ma \\ National-Local Joint Engineering Laboratory, Shenyang Jianzhu University, \\ Shenyang, China \\ ${ }^{a}$ E-mail: chenhui@sjzu.edu.cn, ${ }^{b}$ E-mail: 18309899360@163.com \\ Tao Wang \\ Chinese people's liberation Army of Military Representative Office in \\ Shenyang Aircraft Industry (Group) Co, Ltd \\ Shenyang, China \\ Guo-Qing Nie and Zhi-Jun Shang \\ BaiCheng ZhongYi Precision Forging Company Limited \\ Baicheng, China
}

\begin{abstract}
According to the production process of precision forging for blank parts, to investigate the feasibility that recovering the waste heat from forging process by heat pump technology. It has designed a new cooling system by the heat hump on the basics of analyzing the thermodynamic parameters and heat pump working principle, in addition to reducing the heat pollution caused by the cooling tower, the process waste heat is recovered. Counting the heat supply in the process of production and the heating of the whole plant need according to the thermodynamic principles, on the basis of the above, it design a water supplying and heating system based on the heat pump. It is concluded that using heat pump technology to recover the waste heat in forging process is feasible. It put forward a scheme that the waste heat main rely on the reservoir, groundwater assisted under the premise of the waste heat recovery and meeting the requirements of process cooling water, getting the reservoir's volume is $450 \mathrm{~m}^{3}$.
\end{abstract}

Keywords: Heat Pump; Waste Heat Recovery; Energy Conservation; Groundwater.

\section{Introduction}

China is currently facing two major problems of environmental pollution and energy shortage. 13th Five-Year national planning stressed the importance of energy saving and emission reduction. The $70 \%$ energy consumption of our

\footnotetext{
* This project was financially supported by the National $12^{\text {th }}$ Five-Year Plan for Science and Technology Program (Project no. 2011BAJ02B03-03).
} 
country comes from the industrial field [1] Plays a leading role in the field of manufacturing industry, but the forging industry is the main source of high energy consumption in the industrial manufacturing. The energy consumption of forging workshop mainly from the intermediate frequency electric furnace, the electrical energy into heat forging work. Because the production process is relatively backward, unreasonable production structure, and the heat utilization efficiency is low, causing heat has not been fully utilized, so that the unit GDP energy consumption is relatively high. To make full use of energy, reducing environmental pollution and how to recycle waste heat as the main measures to reduce energy consumption per unit of GDP. The heat pump is a part of the energy consumption of low grade heat transfer from low temperature heat source to the heat source device [2] so the use of forging equipment transformation has become a major way to forge energy-saving heat pump. This paper is mainly aimed at forging a Limited by Share Ltd in plant expansion, winter heating effect is not good, the cooling system water craft designed to heat pump technology as the foundation, the forging workshop in the production process of waste heat recovery using heat pump use, to solve the heating and provide a new system to meet the requirements of process water.

\section{Analysis of Hot Forging System}

Connecting rod of automobile engine plays an important role; the manufacturing technology level will directly affect the engine performance. Connecting rod strength affects the use performance of connecting rod, so the whole working process of the connecting rod, the connecting rod is difficult to processing and forging parts. In a Precision Forging Co., Ltd. has China's first full introduction of precision forging production line, the level of its technology reached the world advanced level, to fill the domestic gap, connecting rod forging production process was shown in Figure 1.

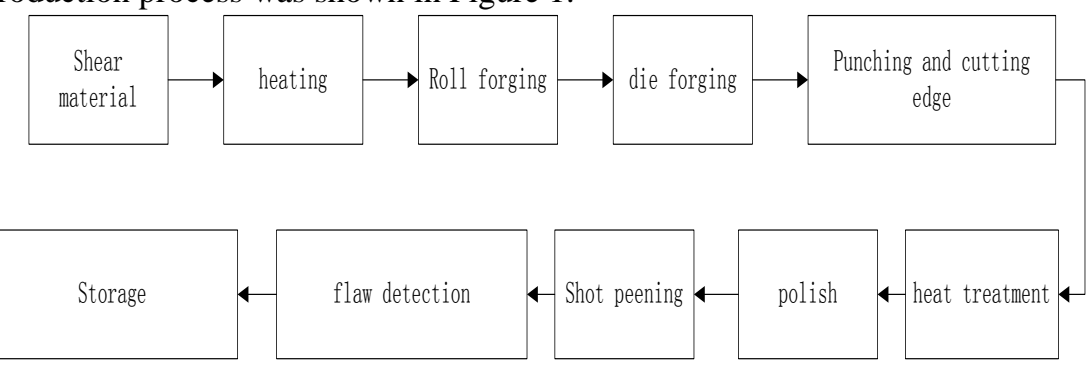

Fig. 1. Production process

In the production of precision forging, the blank part was heated to 1200 to $1240{ }^{\circ} \mathrm{C}$ by the intermediate frequency induction furnace to meet the following 
process temperature requirement. The temperature dropped to 900 to $950^{\circ} \mathrm{C}$ [3]. After roll forging, forging, punching press open cut edge process. After normalizing air cooling to room temperature, and then grinding, shot blasting, flaw detection. Medium frequency induction furnace ,Programmable controlled hydraulic hammer require certain condition of cooling water in order to ensure the tooling system, in order to ensure the normal operation of the intermediate frequency furnace, a reservoir was build in the workshop, using the circle water to cool it. The water inlet temperature of the cold source of the intermediate frequency furnace and the power supply was 20 to $35^{\circ} \mathrm{C}$, and the water outlet temperature was 25 to $40{ }^{\circ} \mathrm{C}$ and the average temperature rose $5{ }^{\circ} \mathrm{C}$. The temperature of the circulating water get higher during the heating process, in order to ensure the normal operation of the equipment, the cooling tower was used to cool the circulating water in the original process. The cooling tower was a device which took the water as a coolant through the outer circulation system to function in the inner circulating surface, and used water to directly contact with the air, heat and cold exchange generates steam and the evaporation took away heat to reduce the temperature of the inner circulating system. The cooling tower not only caused the waste of heat energy, but also caused the heat pollution. Moreover, the cooling tower was difficult to repair in winter.

\section{Waste Heat Recovery System}

Through analysis of the production process, getting the conclusion is that the waste heat can be recovered mainly is from circulating cooling water. The waste heat mainly comes from medium frequency induction furnace, Programmable controlled hydraulic hammer. Waste heat recovery system according to the functional requirements can be divided four parts waste heat recovery, control system, underground cistern, water supply, waste heat recovery systems as shown in Figure 2. 


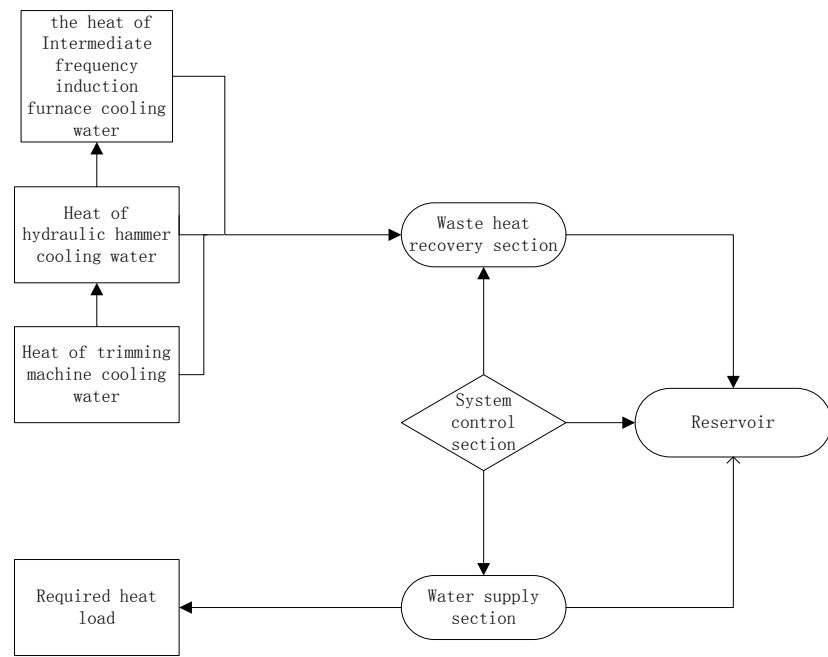

Fig. 2. Composition of waste heat recovery system.

Waste heat recovery system provide the required cooling water for the entire production process the heat pump began to work on the recycling of heat to cool down the heat when the cooling water temperature is too high to affect the normal work. Heat pump cold end extract heat from the circle water to heat pump hot end thereby reaching the effect of waste heat recovery. The principle of waste heat recovery system is shown in Figure 3.

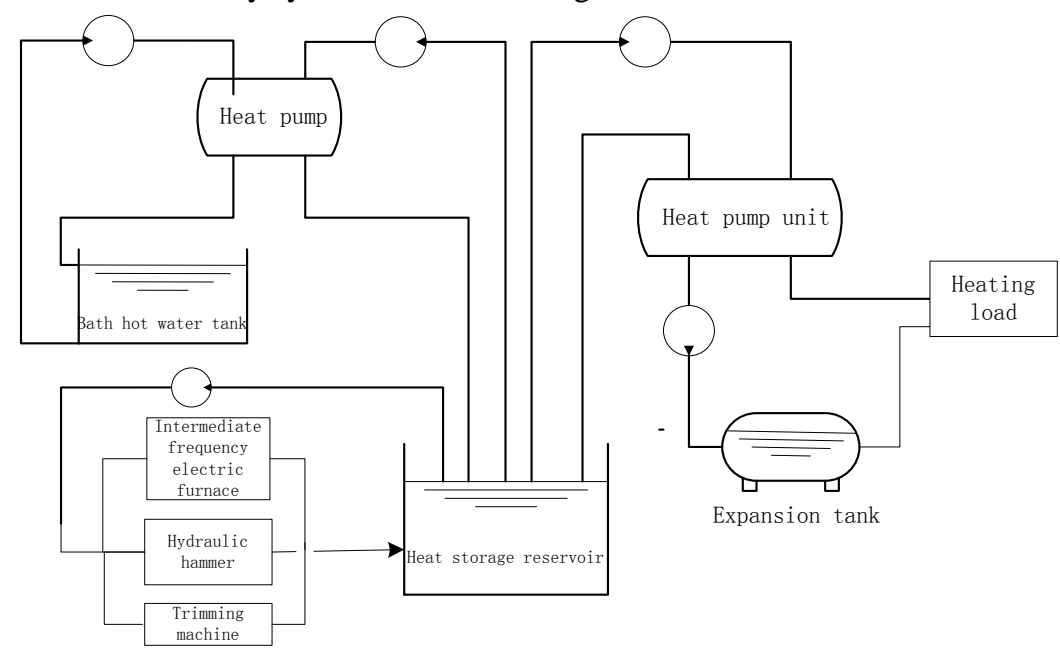

Fig. 3. Principle of waste heat recovery system. 


\section{Thermodynamic Analysis of Waste Heat Recovery System}

\subsection{Analysis of heat transfer mode}

The heat transfer mode in this system mainly is heat conduction and convection heat transfer.

(1) Heat conduction is the phenomenon that the heat transfer from the high temperature to the low temperature depends on the thermal motion of the micro particles when the relative displacement of the parts is not occurred. The main forms of heat transfer in solids are heat conduction, in the static liquid and gas layer by layer transfer, in the dynamic case is often accompanied by convection. The heat conduction process always occurs in the same object in different temperature or in the two contacts with the temperature difference between the object, the object in the heat conduction process between the various parts does not exist macroscopic relative displacement.

(2) Convective heat transfer is a phenomenon of heat transfer due to the movement of particle position in the fluid, which causes the temperature to be uniform [4]. The convective heat transfer, which is often encountered in the engineering, is the heat transfer process of fluid flow through the solid wall. And the convective heat transfer is the combined action of the thermal convection and the heat conduction process. Relative displacement of fluid exists in the process.

When a certain temperature $t_{f}$ of fluid flow through the surface temperature $t_{w}$, the surface area of the solid is A, applying Newton cooling formula to calculate the exchange heat [5].

$$
\begin{gathered}
\emptyset=\mathrm{qA}=\mathrm{h} \Delta \mathrm{tA}=\Delta \mathrm{t} /(1 / \mathrm{hA}) \\
\mathrm{q}=\mathrm{h} \Delta \mathrm{t} \\
\Delta \mathrm{t}=\left|\mathrm{t}_{\mathrm{w}}-\mathrm{t}_{\mathrm{f}}\right|
\end{gathered}
$$

In this type $\mathrm{h}$ mean Surface heat transfer coefficient $\mathrm{q}$ means Heat flux density. A mean heat transfer area $\mathrm{w}, \mathrm{t} \mathrm{f}$, respectively means wall surface temperature and the fluid temperature (DEG C).

\subsection{Thermal equilibrium calculation}

\subsubsection{Calculation of waste heat of the original production process}

The first method: according to the amount of cooling water

3 Circulating water pumps open (One road only opened a pump, the other opened all the pump) one pump water volume was $160 \mathrm{~m}^{3} / \mathrm{h}$ Centrifugal pump parallel flow increased, pipeline resistance, pressure with the increase in the 
flow of the corresponding increased, resulting in a decline in the efficiency of the pump directly. The flow rate of two parallel pumps is calculated by $85 \%$ the mount of cooling water was $160+(160+160) * 85 \%=432 \mathrm{~m}^{3} / \mathrm{h}$.

The cooling power flow $(\mathrm{KW})=1.163^{*}$ flow rate $\left(\mathrm{m}^{3} / \mathrm{h}\right) *$ range of temperature (it got $4{ }^{\circ} \mathrm{C}$ generally) cooling heat value was $432 * 4 * 1.163=2009$ $\mathrm{kW}$

This data was the amount of heat produced during the summer. Actually in winter cooling water transportation in the process, heat loss is larger in the pipeline, the actual cooling tower releasing heat was less than that in summer, and winter heat loss calculated in accordance with $90 \%$ of the summer, winter cooling heat value was $2009 * 90 \%=1808 \mathrm{~kW}$.

The second methods: calculating according to the heating equipment input power

According to the law of conservation of energy, the heat energy of the heating equipment comes from the input electric energy, mechanical energy, the transformation of heat energy

1. The medium frequency furnace apparatus: the input power can cause the coil in high temperature condition, high temperature heating castings to red state, and then pressing casting, less heat was taken away by casting, 90 percent of the heat was taken by cooling water. Producing by intermediate frequency furnace heat value was $85 \%$ of the input power.

2. Program controlled hydraulic hammer: attack time interval can be pre selected, the biggest blow to energy $25 \mathrm{~kJ}$.

3. Air compressor equipment: it was a device to provided compressed air with a certain pressure .Press-air temperature got higher suddenly when air compressor equipment made mechanical energy convert to pressure energy, oil and gas mixture temperature reached $100 \sim 75{ }^{\circ} \mathrm{C}$ because of the friction in running. These oil and gas mixture with pressure discharged heat in to the air; this part of the heat is about 75 percent the input power of the air compressor. The machine itself still contained heat in addition to the oil and gas mixture containing heat, so the air compressor can recover the heat is about the input power of $80 \%$ [6].

The above analysis according to the input power accounting total heat value is 7 sets of $300 \mathrm{~kW}$ intermediate frequency furnace heat value $7 * 300 * 85 \%=1785 \mathrm{~kW}$

2 sets of program controlled hydraulic hammer heat value $25 * 2 *=50 \mathrm{~kW}$

2 sets of air compressor heat value $(110+185) * 0 \%=236 \mathrm{~kW}$

The heat value of other heating equipment for the time being ignored

The above calculation the heat of in total one hour $1785+50+236=2071 \mathrm{~kW}$

According to the above two methods to calculate the heat value of the waste 
water, the heat value was $1808 \mathrm{~kW}$ calculated according to the cooling tower water temperature and water flow ,the heat value was $2071 \mathrm{~kW}$ according to the heating equipment input electric energy into thermal energy.

It was relatively correct that calculate heat according to the cooling waters amount and temperature difference Because there was deviation between rated capacity and actual quantity of the cooling tower, and the heat value was smallest calculated according to the circulating cooling water, so determine the heat value according to the most unfavorable conditions, it can get $1808 \mathrm{~kW}$ heat from the waste heat water. This was both environmental protection and energy saving in the face of waste heat energy and building heating effect not well.

\subsubsection{Office building and plant heating required heat load}

1. Office building heat load calculation: office building area of $3000 \mathrm{~m}^{2}$, according to the area load index calculation method, the heat load is $3000 \times 65$ $\mathrm{m}^{2}=195 \mathrm{~kW}$.

2. Thermal load calculation of workshop

After checking the $<$ mining warm, ventilation and air conditioning design specification > (GBJI19-87), the volume thermal index method should be adopted in calculating when the building clearance high is higher than 4 meters, workshop room calculated temperature is 10 to 15 degrees.

$$
\mathrm{Q}_{\mathrm{n}}=\mathrm{qv} \times \mathrm{V} \times\left(\mathrm{t}_{\mathrm{n}}-\mathrm{t}_{\mathrm{w}}\right)
$$

$\mathrm{Q}_{\mathrm{n}}$ - heating design of building heat load, $\mathrm{W}$;

$\mathrm{V}$ - The external volume of the building, $\mathrm{m}^{3}$;

$\mathrm{t}_{\mathrm{n}}$ - heating room temperature, ${ }^{\circ} \mathrm{C}$;

$\mathrm{t}_{\mathrm{w}}$ - heating outdoor calculation temperature, ${ }^{\circ} \mathrm{C}$

$\mathrm{q}_{\mathrm{v}}$ - Heating volume index of building, $\mathrm{W} / \mathrm{m}^{3} .{ }^{\circ} \mathrm{C}$, It mean that the heating load of Each cubic meter the peripheral volume of buildings when the temperature difference between indoor and outdoor is $1{ }^{\circ} \mathrm{C}$, It is mainly related to the structure and shape of the building. Plant generally take $0.5-0.8 \mathrm{~m}^{3}$. The plant volume was $21000 * 8=168000 \mathrm{~m}^{3}$, calculation of temperature indoor was $10{ }^{\circ} \mathrm{C} \mathrm{C}$, the total heat load was $0.5 \times 168000 *[10-(-26)]=3024 \mathrm{~kW}$.

\subsubsection{Heat load of shower needed}

In accordance with the workers to use 50 degrees hot water bath $80 \mathrm{~L}$, each time 1 hour to calculate the required heat: according to $q=\mathrm{cm} \Delta \mathrm{t}$ calculate the required heat was $2.0 \times 103 \mathrm{~kJ}$, which was needed to heat the two hours, total heat load was $277 \mathrm{~kW}$, it can meet the needs of 200 workers bathing in hot water According to the above calculation, Total heat load required for the project was 
$3024195277=3496 \mathrm{~kW}$, according to the load allocation, determine the plant required total heat load was $3500 \mathrm{~kW}$. Select 3 sets heat pump the heat input power of $286 \mathrm{~kW}$ (supply and return water temperature was $60 / 40^{\circ} \mathrm{C}$ ) through the calculation of waste heat and heat supply required heat load, waste heat cannot meet the heating demand and the rest of the heat needed by other ways to supplement. According to the heat pump host selection models, 3 sets of heat pump units need $3 *(1200-286)=2740 \mathrm{~kW}$, Heat source water in accordance with the 6 degree calculation ,required the mount of the heat source of water was $2740 \mathrm{kw} * 0.86 / 6=400 \mathrm{~m}^{3}$.

\subsection{Heat balance analysis and calculation of reservoir}

From 7 o'clock to 24 waste heat has been produced in the production but the heating is intermittent so the establish a large enough reservoir to store hot and cold water circulation .During the boiler heating period, heating supply water temperature was about $60{ }^{\circ} \mathrm{C}$, back water temperature was about $45{ }^{\circ} \mathrm{C}$, each time supplying 2 hours, 3-4 times a day, the office temperature was about $18^{\circ} \mathrm{C}$, the workshop temperature was about $10^{\circ} \mathrm{C}$. Analyzing according to the data, outlet temperature of heat pump unit is $60^{\circ} \mathrm{C}$, Start heating for 3 hours, 3 hours to stop machine, the operation time is 12 hours when it is the coldest weather. According to the calculation cooling water supply $1808 \mathrm{~kW}$ heat to the reservoir per hour, heat pump getting heat per hour from the reservoir was $3 *(1200-286)$ $=2740 \mathrm{Kw}$.

Table 1. The tank heat balance analysis

\begin{tabular}{|l|l|l|l|l|}
\hline Heating time & $\begin{array}{c}\text { Waste heat } \\
\text { release heat } \\
\text { KW }\end{array}$ & $\begin{array}{c}\text { Upper time tank } \\
\text { storage heat } \\
\text { KW }\end{array}$ & $\begin{array}{c}\text { Heat } \\
\text { absorption } \\
\text { KW }\end{array}$ & $\begin{array}{c}\text { Tank dynamic } \\
\text { equilibrium heat } \\
\text { KW }\end{array}$ \\
\hline $7: 00-10: 00$ & +5424 & & -8220 & -2796 \\
\hline $10: 00-13: 00$ & +5424 & 0 & 0 & +5424 \\
\hline $13: 00-16: 00$ & +5424 & +5424 & -8220 & +2628 \\
\hline $16: 00-19: 00$ & +5424 & +2628 & 0 & +8052 \\
\hline $19: 00-22: 00$ & +5424 & +8052 & -8220 & +5256 \\
\hline $22: 00-01: 00$ & +5424 & +5256 & 0 & +8872 \\
\hline $01: 00-04: 00$ & 0 & +8872 & -8220 & +652 \\
\hline $04: 00-07: 00$ & 0 & +652 & 0 & +652 \\
\hline
\end{tabular}

On the table, heat production time is from 7:00 to 24:00, a total of 12 hours of heating time per day. Calculate the volume of the reservoir according to the above table analysis

The minimum heat in the reservoir must meet the heat pump required in 3 hours, the quantity of heat it needed was $8220 \mathrm{~kW}$ in 3 hours, $2740 \mathrm{~kW}$ per 
hour, Heat source water in accordance with the 6 degree calculation ,required the volume of the heat source of water was $2740 \mathrm{kw} * 0.86 / 6=400 \mathrm{~m}^{3}$.

In order to make full use of waste heat, using the heat storage reservoir to store the cooling water. Reservoir volume should meet at least 3 hours heat storage and reservoir water temperature rising no more than $11^{\circ} \mathrm{C}$ was appropriate, the volume was $5424 * 0.86 / 11=424 \mathrm{~m}^{3}$, the net volume of the pool design $450 \mathrm{~m}^{3}$.

The waste heat water was stored in the water reservoir in the heating stopping time. Heat pump extract the heat in the reservoir while cooling water provided heat to the reservoir in the heating time. Heat pump unit would operate long time in the coldest day the storage heat in the reservoir couldn't meet the unit required, at the same time, automatic temperature control open to provide well water to the reservoir as the heat source, when the water temperature was reduced to $6^{\circ} \mathrm{C}$.

\section{Conclusion}

(1) By precision forging production process analysis and thermodynamic calculation, construction of the waste heat recovery system, demonstrates the use of heat pump technology in recovery of waste heat scheme is feasible. The heat pumps extract waste heat from the storage reservoir, combined with local favorable groundwater, so the heat can meet the factory and living required, and the project reduces heat pollution to the environment.

(2) According to the requirements of working conditions, it can get 1808 $\mathrm{kW}$ heat from the cooling water that to ensure precision forging equipment operate well, and building need heat load was $3500 \mathrm{~kW}$, Heat pump unit extracted heat from $450 \mathrm{~m}^{3}$ heat storage reservoir, local $10{ }^{\circ} \mathrm{C}$ groundwater as a heat source, so it can provided the heat all needed without affecting the production process conditions.

\section{Reference}

1. Zhao Wei qiang, Chen Hui, Wang Jibing, Yang Shiyuan, Liu Gang. Process analysis and design of waste heat recovery system for the production process of drag reducing agent $[\mathrm{J}]$. mechanical and electrical products development and innovation, 2015,03:37-40

2. Wang Zhigang, Zheng Fa, Zhao Wei. A factory using heat pump technology to recover the technical transformation of industrial waste heat [J]. power generation and air conditioning, 2014, 03:58-60+48

3. Xu Feifei, Feng Huisheng, Liu Yefeng. Research progress of industrial process waste heat recovery and utilization technology [J]. Chemical 
industry and engineering, 2012, 01:57-64.

4. Zhang Hui. Design and Simulation of forging process of aluminum alloy connecting rod [J]. Casting technology, 2011, 06:871-875.

5. Wang Xudong. The circulating water waste heat recovery heating analysis and research [J]. Chinese chlor alkali, 2014, 11:45-47.

6. Lu Zhenqian, Sheng Zhao Kun. The principle and application effect of heat energy recovery of air compressor [J]. Cotton textile technology, 2011, 02 $11-13$

7. Javani, N; Dincer, I.; Naterer, G.F. Thermodynamic analysis of waste heat recovery for cooling systems in hybrid and electric vehicles [J]. Energy, 2012, 46(1): 109-116.

8. Wei Ming shan, Fang Jinli, Ma Chao chen, Danish Syed Noman. Waste heat recovery from heavy-duty diesel energy exhaust gases by medium temperature ORC system [J] Science China: Technological Sciences, 2011, 54(10): 2746-2753.

9. Chen Ze shao, Tao Wen quan, Zhu Yan wen, Hu Peng. Performance Analysis of Air-Water Dual Source Heat Pump Water Heater with Heat Recovery [J]. Technological Sciences, 2012, 55(8):2148-2156.

10. Shu Ge Qun, Wang Xuan, Tian Hua, Liang YouCai, Liu Yu, Liu Peng. Analysis of an electricity-cooling cogeneration system for waste heat recovery of gaseous fuel engines [J]. Science China (Technological Sciences), 2015, 01:37-46.

11. Lei Jie, Lu Xin jiang, LI Yibo, Huang Ming hui, Zou Wei. Approximate-model Based Estimation Method for Dynamic Response of Forging Processes [J]. Chinese Journal of Mechanical Engineering, 2015, 03:565-572.

12. Tian Hua, Zhang ChengYu, LI XiaoNing, Shu GeQun. Experimental investigation on diesel engine's waste heat capacity under mapping characteristics [J]. Science China (Technological Sciences), 2015, 01:9-18.

13. Wang Zhiqi, Liu Liwen Xia Xiaoxia, Zhou Naijun. Dynamic test on waste heat recovery system with organic Rankine cycle [J]. Journal of Central South University, 2014, 12:4607-4612. 